\title{
Flexural and shear performance of an innovative foam-filled sandwich panel with 3-D high density polyethylene skins
}

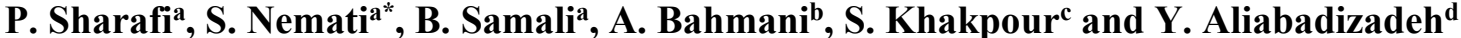

${ }^{a}$ Centre for Infrastructure Engineering, Western Sydney University, Australia

${ }^{b}$ Department of Mechanical and Mechatronics Engineering, University of Waterloo, 200 University Ave. West, Waterloo N2L 3G1, Canada ${ }^{c}$ MIPT Group, University of Oulu, Finland

${ }^{d}$ University of Maryland, College Park, Maryland, USA

\begin{tabular}{l}
\hline A R T I C L EI N F O \\
\hline Article history: \\
Received 25 November, 2017 \\
Accepted 15 March 2018 \\
Available online \\
15 March 2018 \\
\hline Keywords: \\
Sandwich panel \\
Polyurethane foam core \\
3-D high density polyethylene \\
skin \\
First-order Shear Deformation \\
Theory (FSDT)
\end{tabular}

\section{Introduction}

Innovative foam-filled sandwich composite structures have attracted attention in the past decade, mainly because of their great comparative advantages such as light weight, high strength, corrosion resistance, durability and speedy construction. These types of sandwich panels are becoming a major role player in modular and rapid assembly construction with a variety of applications in residential and commercial buildings worldwide (Thomsen et al., 2006). These products are popular because they are light, easy to install and have good thermal and acoustic properties. In recent years, considerable research efforts have been continuously looking for new construction materials and efficient designs for such sandwich panels. Various forms of sandwich construction are being produced by combining different skin and core materials, with various geometries and configuration. In addition to their * Corresponding author.

E-mail addresses: s.nemati@uws.edu.au (S. Nemati) 
applications as non-structural building elements, sandwich panels with polyurethane (PU) foam-core and exterior and interior facing materials such as gypsum, engineered wood or some composite materials are being used as structural members in building construction (Thomsen et al., 2009).

With regard to the literature, a wide range of studies on the foam-filled composite panels are on those made of polyurethane (PU) foam-core (Allen, 2013). Fam et al. (2010) explored the feasibility of fabrication and flexural performance of panels composed of low-density polyurethane foam core sandwiched between two GFRP skins. Reis and Rizkalla (2008) presented an innovative 3-D glass fibre reinforced polymer (GFRP) panels with foam-core designed to overcome delamination problems, typically encountered in traditional sandwich panels. Sharafi et al. (2010) studied the flexural behaviour of sandwich panels fabricated by laminating two glass fibre reinforced polymer skins to a prefabricated polyurethane foam core. They showed that flexural strength and stiffness increased substantially, as the core density was doubled. Manalo (2013) investigated the structural behaviour of an emerging prefabricated wall system made up of glass fibre reinforced rigid polyurethane foam and Magnesium Oxide board. Their results indicated that the behaviour of the composite walls is governed by the strength of the board. Wang et al. (2014) focused on the bending behaviour of an innovative sandwich panels with GFRP face sheets and a foam-web core (GFFW) panels, where t]heir experimental study demonstrated that the ultimate bending strength and initial bending stiffness can be significantly enhanced by increasing web thickness. Kumar and Soragaon (2014) studied on the effect of change thickness of fibre reinforced polymer (FRP) facing sheets and inserts on the flexural behaviour of sandwich panels with a constant total thickness. Tuwar et al. (2015) evaluated three different polyurethane foam configurations for (GFRP) foam-core sandwich panels. Lv et al. (2017) studied on bending properties of 3-D honeycomb sandwich structure composites with three different cross section shapes. Sharafi (2010) and Sharaf and Fam (2010) addressed the flexural performance of sandwich panels composed of a polyurethane foam core and GFRP skins. They also presented numerical modelling of the flexural behaviour of sandwich panels composed of woven glass fibre reinforced polymer skins and polyurethane foam core, including various patterns of glass fibre reinforced polymer ribs, as well as different densities of cores (Sharaf and Fam, 2012). In a similar study, Dawood et al. (2010) evaluated the two-way bending behaviour of 3-D GFRP sandwich panels consisting of GFRP skins with a foam core and through-thickness fibre insertions. In a comprehensive study, Mostafa et al. (2015a) studied composite sandwich panels composed of GFRP skin with polyvinylchloride and polyurethane foam core, reinforced with shear keys under static bending load, while the semicircular shear keys inserts were made of chopped strand glass fibre impregnated with epoxy resin. They conducted series of quasi-static tests, while the flexural response of the sandwich panel with and without shear keys has been evaluated under four-point bending test. A significant improvement in the flexural stiffness and strength of the panel incorporated with shear keys accompanied with a good correlation with the analytical results were observed. They also tested light weight sandwich structures through four-point bending tests to characterize their flexural behaviour (Mostafa et al., 2015b), and tried to extend the knowledge of mechanical properties of the sandwich structures, by studying the effects induced by inserting semi-circular shear keys between the skin and the foam core (Mostafa, 2015). Since, one of the major failure modes in foam made structures, is the crack growth and brittle fracture, some of the scholars have been investigated the fracture toughness and crack growth resistance of such materials under different tensile and shear loads (Marsavina et. al. 2013,2014; Aliha et al. 2018).

The results of previous studies indicate that the stiffness and strength of a majority of conventional foam-filled sandwich panels hardly meet the structural requirements for use in building floors or walls, at least for standard spans and loads, mainly due to some different failure modes such as delamination of the skins from the core, buckling or wrinkling of the compression skin, flatwise crushing of the core or rupture of the tension skin. The main weaknesses of these panels stem from the low stiffness and strength of the core, and the skin's susceptibility to delamination and buckling, owing to the local mismatch in stiffness and the lack of reinforcements bridging the core and the skins (Correia et al., 2012). The use of stitches for connecting the two side skins (Potluri et al., 2003), or use of reinforcing 
ribs (Dawood et al., 2010) are two popular strengthening techniques being employed for improving the mechanical performance of standard sandwich panels.

This study proposes a new geometry design and material to enhance the properties of the foam-filled sandwich panels with regard to such failure modes. A 3-D high density Polyethylene (HDPE) sheets are used as the skins with a thickness as $2 \mathrm{~mm}$, and high-density PU foam is used as the core with a total thickness as $100 \mathrm{~mm}$, as illustrated in Fig. 1. Using the HDPE sheets, manufactured with approximately 1200 studs per square meter, higher pull-out and delamination strength, as well as better stress distribution, and buckling performance can be achieved. The studs also improve the resistance of the face sheets and foam-core from debonding and increasing the interface strength between the foam-core and the face sheets. This innovative sandwich panel was developed at the centre for infrastructure engineering (CIE) in the Western Sydney University to be used as modular walls and floors in rapid assembly buildings for semi-permanent post disaster housing.
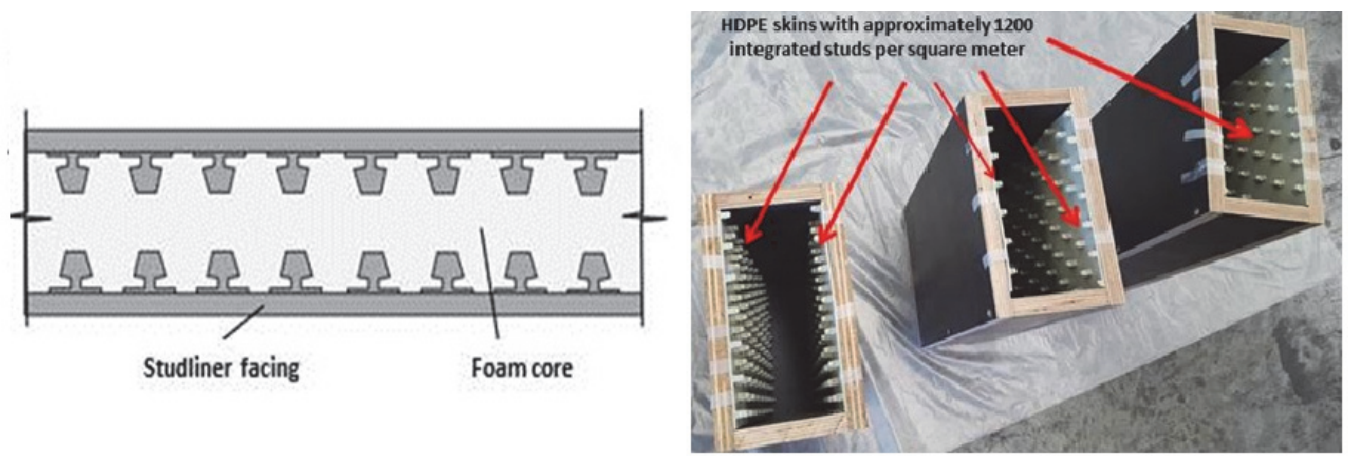

Fig. 1. Introduced sandwich panel with HDPE skins and PU foam-core

\section{Material characterization}

This section reports the detailed descriptions of the tests carried out for material characterization of the constituent materials i.e. PU rigid foam and 3-D HDPE skin sheets. To evaluate the basic material properties, in addition to using the manufacturers' data, some experimental tests were performed.

\subsection{Polyurethane foam used in the sandwich panel}

Polyurethane high-density rigid foam with a density of $192 \mathrm{~kg} / \mathrm{m}^{3}$ was selected for the core material, according to the results the preliminary finite element models. Table 1 shows the PU foam's manufacturing and mechanical properties, provided by the manufacturer, and validated in the laboratory according to the ASTM 1730 standard specification for rigid foam for use in structural sandwich panel cores (Garrido et al., 2016; ASTM-E1730, 2015).

Table 1. Mechanical and manufacturing properties of the selected PU rigid foam

\begin{tabular}{|c|c|c|c|}
\hline \multicolumn{4}{|c|}{ Mechanical Properties of the PU foam } \\
\hline $\begin{array}{l}\text { Density } \\
\left(\mathrm{kg} / \mathrm{m}^{3}\right)\end{array}$ & $\begin{array}{c}\text { Compressive yield strength } \\
(\mathrm{MPa})\end{array}$ & $\begin{array}{c}\text { Tensile yield strength } \\
\text { (MPa) }\end{array}$ & Shear yield strength (MPa) \\
\hline 192 & 3.51 & 1.896 & 1.034 \\
\hline \multicolumn{4}{|c|}{ Manufacturing Properties } \\
\hline Cream time & Gel time & Tack free time & Free rise cup density \\
\hline $35-40 \mathrm{sec}$ & $94 \pm 4 \mathrm{sec}$ & $115 \pm 5 \mathrm{sec}$ & $280-300 \mathrm{~kg} / \mathrm{m}^{3}$ \\
\hline
\end{tabular}

Using a uniaxial load machine (Fig. 2), three cubic specimens (dimensions: $50 \mathrm{~mm} \times 50 \mathrm{~mm} \times 50 \mathrm{~mm}$ ) were tested based on the ASTM E1730 and ASTM D1621 (ASTM-D1621, 2010) standards at a loading rate of $5 \mathrm{~mm} / \mathrm{min}$ in order to identify the structural properties of the rigid PU foam. 


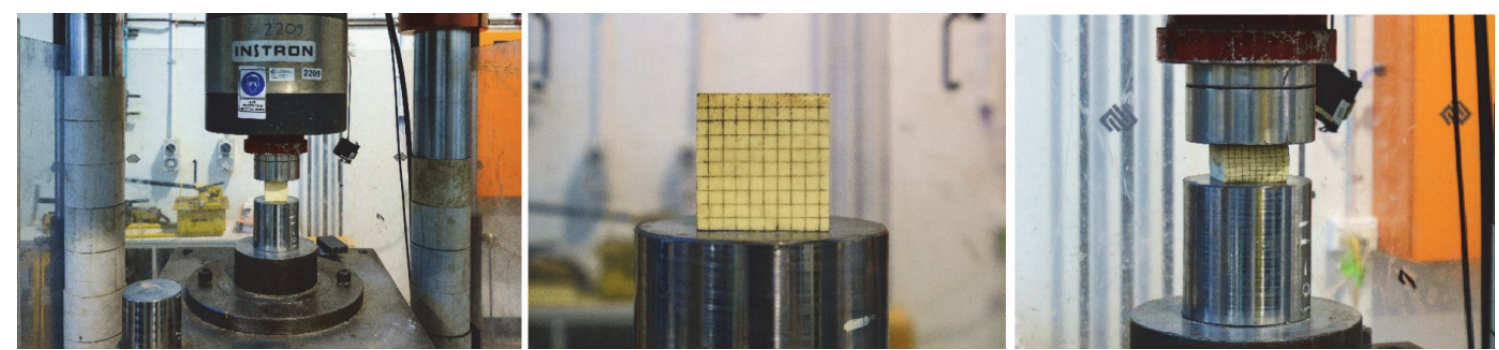

Fig. 2. Uniaxial load test for determining the compressive behaviour of PU foam

Table 2 shows the yield stress and elastic modulus for each specimen, and Fig. 3 illustrates the stressstrain curves in the elastic region and failure graph, respectively. The curves show that this type of PU foam, which is made of a 100:110 weight ratio mixture of AUSTHANE POLYOL AUW763 and AUSTHANE MDI, can undertake considerable deformation before the failure. These stress-strain curves are relatively linear in the elastic region, with a yield region at an average stress of $3.51 \mathrm{MPa}$, and an average elastic modulus of 135.5 MPa.

Table 2. Yield stress and elastic modulus of PU specimens

\begin{tabular}{rcc}
\hline & $\sigma_{\mathrm{y}}(\mathrm{MPa})$ & $\mathrm{E}(\mathrm{MPa})$ \\
\hline Test 1 & 3.6 & 130 \\
Test 2 & 3.52 & 137.9 \\
Test 3 & 3.45 & 132.9 \\
Test 4 & 3.5 & 141.3 \\
Test 5 & 3.48 & 136.7 \\
\hline Average & 3.51 & 135.5 \\
\hline Standard Deviation & 0.056 & 5.05 \\
\hline
\end{tabular}
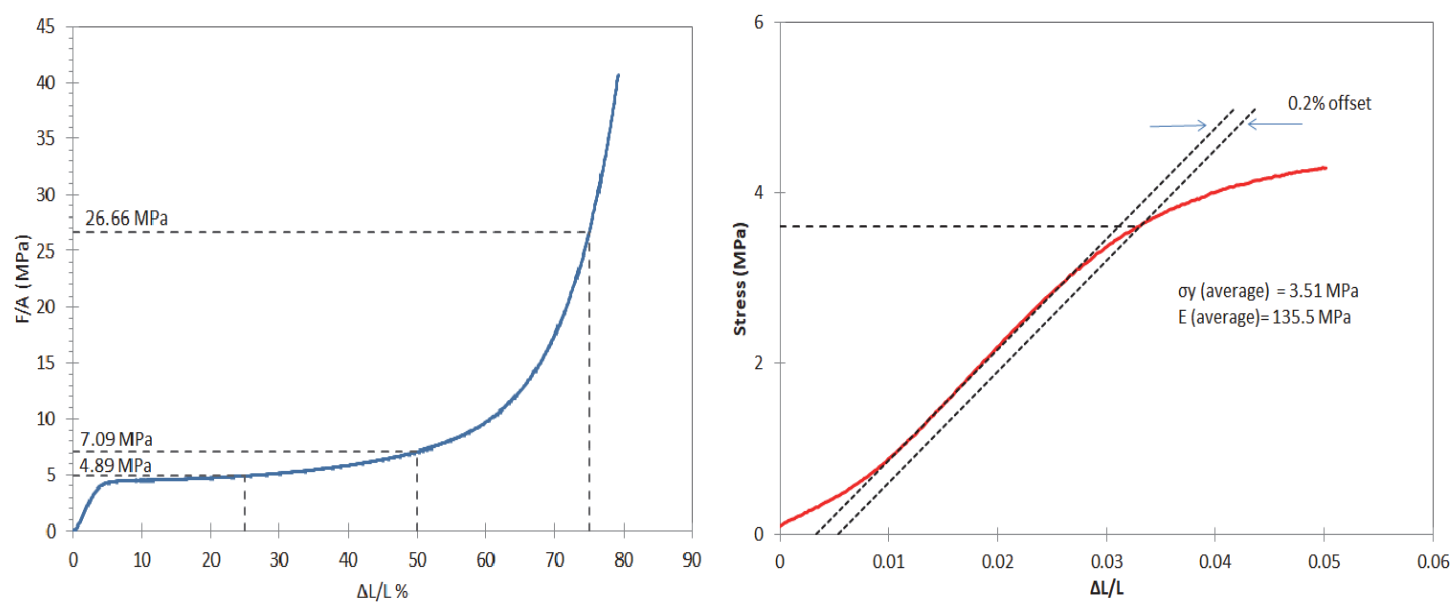

Fig. 3. Results of the uniaxial load test on PU foam, left: total behaviour and right: elastic range

The yield behaviour can be explained by the buckling of the foam's internal walls. Scanning Electron Microscopic images (SEM), provided before and after compression test, shown in Fig. 4, substantiate such behaviour. A long and rather flat plateau was followed. Then, a densification (hardening) region was created by a gradual stress increase when the cell walls were stacked prior to final densification. In this range of loading, no visible signs of failure were observed. Residual displacement of the collapsed foam however, occurs once the unloading stage was complete. 


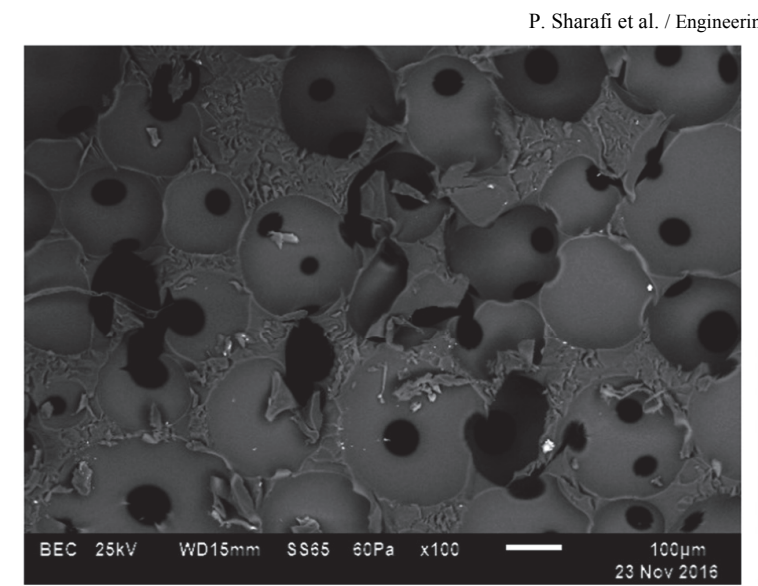

(a)

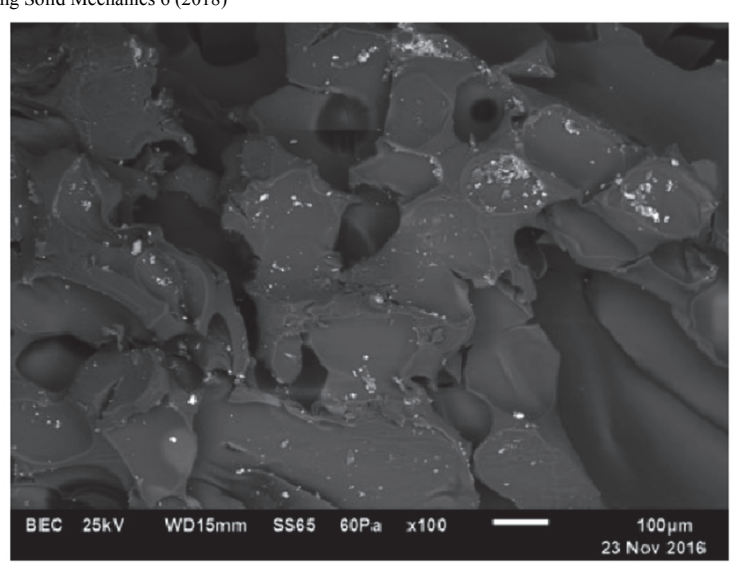

(b)

Fig. 4. Images from the scanning electron microscope on the PU specimens (a) before and (b) after the compression test.

\subsection{High density Polyethylene sheets}

The face sheets of the sandwich panels are made of 3-D HDPE (High Density Polyethylene) sheets primarily produced as a concrete embedment liner to provide protection from mechanical damage and a corrosive and erosive environment. In addition to resistance to chemical and environmental threats, its relatively high strength, and in particular its 3-D studded face with approximately 1200 studs per square meter, can effectively contribute to the sandwich composites' structural performance by providing high pull out strength, minimum lateral movement of the skin, and stronger bonding. Four different thicknesses of the sheets were initially investigated $(2 \mathrm{~mm}, 3 \mathrm{~mm}, 4 \mathrm{~mm}$ and $5 \mathrm{~mm})$, and at the end the sheets with $2 \mathrm{~mm}$ tackiness were selected for the sandwich composite. Table 3 shows some mechanical properties of the selected sheet, provided by the manufacturer and validated by experimental tests in the laboratory, in accordance with the ASTM D5199, ASTM D1505 and ASTM D6693 provisions (ASTM-D6693, 2015) at a loading rate of $5 \mathrm{~mm} / \mathrm{min}$.

Table 3. Specifications of the HDPE sheets

\begin{tabular}{|c|c|c|}
\hline Tested Property & Test Method & Nominal value \\
\hline Thickness (mm) & ASTM D 5199 & 2 \\
\hline Density $\left(\mathrm{g} / \mathrm{mm}^{2}\right)$ & ASTM D 1505 & 0.94 \\
\hline Sher strength at yield $(\mathrm{MPa})$ & & 5.2 \\
\hline Elongation at Break (\%) & & 500 \\
\hline Stud pull-out strength $\left(\mathrm{kN} / \mathrm{m}^{2}\right)$ & & $>670$ \\
\hline Notched Constant Tensile Load, hours & ASTM D 5397 & 400 \\
\hline Coefficient of Linear Thermal Expansion, per ${ }^{\circ} \mathrm{C}$ & ASTM D 696 & $1.20 \mathrm{E}-04$ \\
\hline Low Temperature Brittleness, ${ }^{\circ} \mathrm{C}$ & ASTM D 746 & -77 \\
\hline Dimensional Stability, \% (each direction) & ASTM D 1204 & 1 \\
\hline Water Absorption, $\%$ & ASTM D 570 & 0.1 \\
\hline
\end{tabular}

In order to identify the structural behaviour of the skin, in-plane tensile tests were conducted on two principal perpendicular directions (lengthwise and crosswise) of the HDPE sheets, using a universal hydraulic testing machine. Five repeated specimens for each direction of the HDPE face sheet were tested as shown in Fig. 5. Typical tension specimens consisted of flat strips with a total width of $19 \mathrm{~mm}$ and a total length of $115 \mathrm{~mm}$, according to ASTM D6693 standard (ASTM-D6693, 2015). Fig. 6 shows the coupon test results. The 3-D HDPE sheets exhibited a relatively linear elastic response up to a strain of $0.15 \mathrm{~mm} / \mathrm{mm}$ at the yield stress of $19.7 \mathrm{MPa}$ in the lengthwise direction; and to a strain of 0.11 $\mathrm{mm} / \mathrm{mm}$ at the yield stress of $20.6 \mathrm{MPa}$ in the transverse (crosswise) direction, indicating relatively similar behaviour in the elastic range. Since the coupon specimens were cut from 3-D panels, the minor differences in behaviour could be due to the combination of the presence of the studs in different directions, or manufacturing homogeneity of the sheets. A non-linear plastic stress-strain relationship was observed in the higher ranges of strain. Results show the HDPE modulus of elasticity in lengthwise 
118

direction is $\mathrm{E}_{\mathrm{L}}=19.7 / 0.15=131.33 \mathrm{MPa}$, and in crosswise direction is $\mathrm{E}_{\mathrm{C}}=20.6 / 0.11=187 \mathrm{MPa}$. In the computer model average value of $E_{S T U D}=159 \mathrm{MPa}$ is used to model the HDPE as isotropic material.

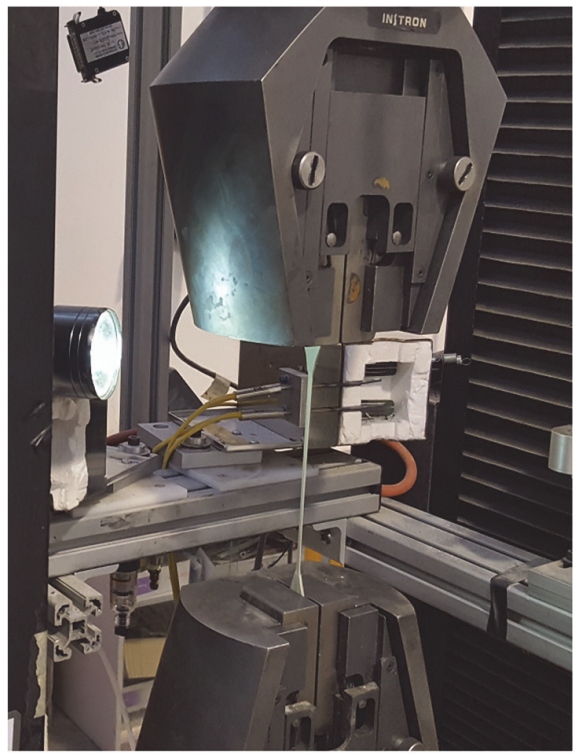

(a)
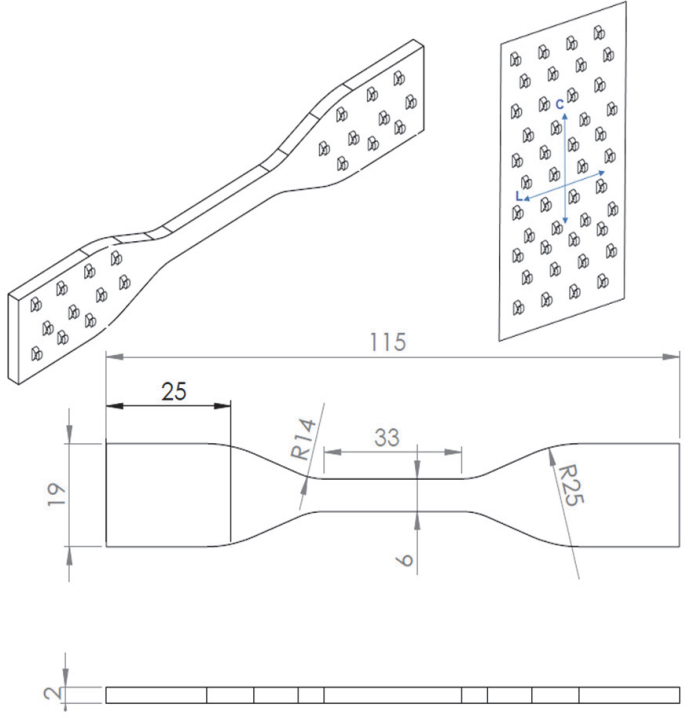

(b)

Fig. 5. HDPE coupon test and specimens' dimensions

\begin{tabular}{|c|c|c|c|}
\hline Test No. & $\begin{array}{c}\text { Applied Load } \\
\text { at Yield Point } \\
\text { (N) }\end{array}$ & $\begin{array}{c}\text { Yeild Stress } \\
\text { (Mpa) }\end{array}$ & $\begin{array}{c}\text { Yeild } \\
\text { Elongation } \\
\text { (\%) }\end{array}$ \\
\hline 1 & 243 & 20.3 & 15 \\
\hline 2 & 221 & 18.4 & 16 \\
\hline 3 & 243 & 20.3 & 15 \\
\hline 4 & 234 & 19.5 & 14 \\
\hline 5 & 237 & 19.8 & 14 \\
\hline Avrage & 236 & 19.7 & 15 \\
\hline $\begin{array}{c}\text { Standard } \\
\text { Deviation }\end{array}$ & 9 & 0.75 & 1.1 \\
\hline
\end{tabular}

\begin{tabular}{|c|c|c|c|}
\hline Tesı Nu. & $\begin{array}{c}\text { Applied Load } \\
\text { at Yleld Polnt } \\
(\mathbf{N})\end{array}$ & $\begin{array}{c}\text { Yeild Stress } \\
(\mathrm{Mpa})\end{array}$ & $\begin{array}{c}\text { Yeild } \\
\text { Elongatlon } \\
(\%)\end{array}$ \\
\hline 1 & 258 & 21.5 & 11 \\
\hline 2 & 243 & 20.1 & 11 \\
\hline 3 & 238 & 19.8 & 10 \\
\hline 4 & 256 & 21.3 & 10 \\
5 & 246 & 20.5 & 14 \\
\hline Avrage & 248 & 20.6 & 11 \\
\hline Standard & & & \\
Deviation & 8.6 & 0.72 & 1.6 \\
\hline
\end{tabular}
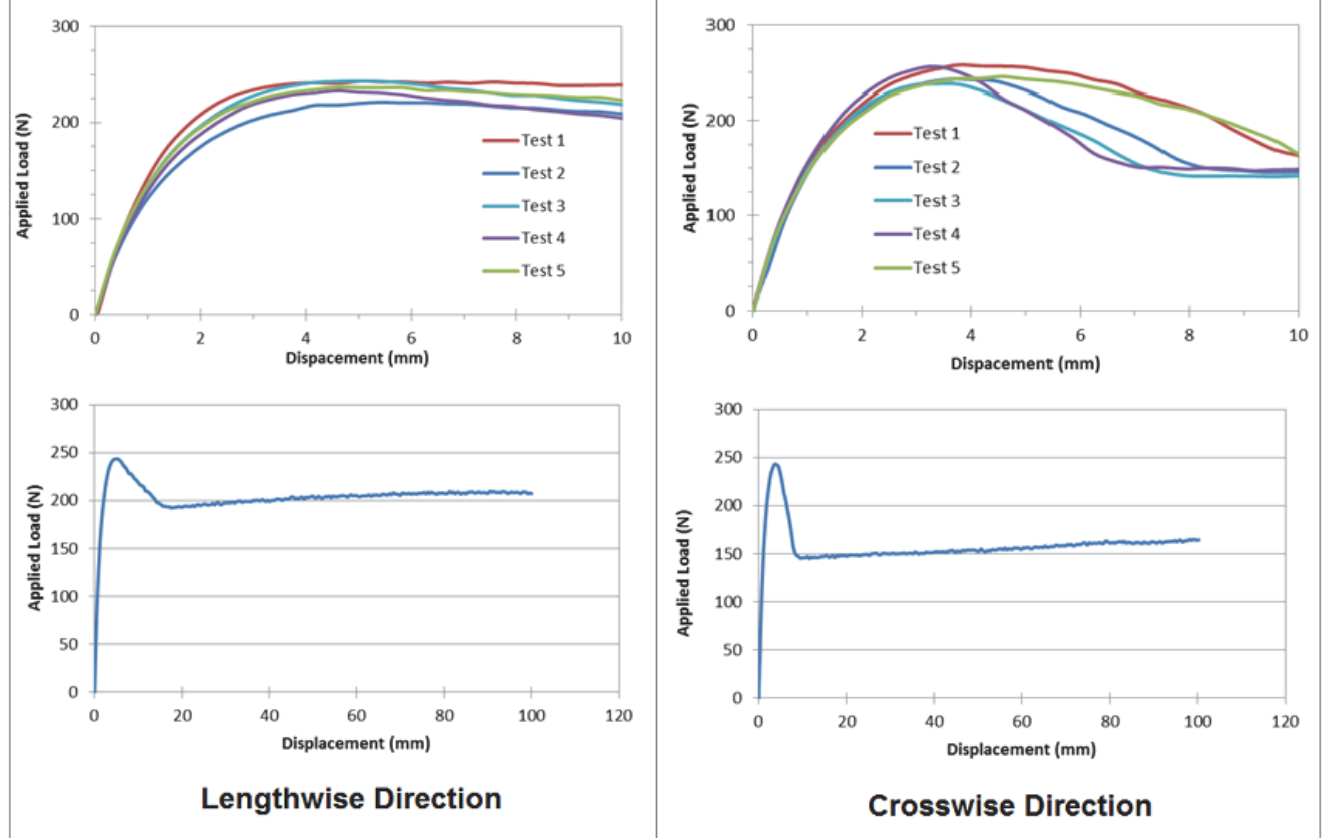

Fig. 6. HDPE coupon tests results for the Lengthwise and Crosswise directions 


\section{Experimental Program}

General speaking, the flexural stiffness of sandwich beams/panels can be calculated using First-order Shear Deformation Theory (FSDT) (Sharafi et al., 2012a, 2012b; Carlsson \& Kardomateas, 2011). The FSDT can also be used to estimate the shear stiffness of each sandwich beam type by fitting the results collected from four-point flexural tests. In this regard, a perfect bond must be assumed to exist between the core and the facings. The bending stiffness can be computed accounting for the deflection components that are associated with bending and shear deformations (Sharafi et al., 2014a, 2014b; Hayes, 2003). This study examined the core shear properties of introduced polyurethane infill-foam composite panels subjected to flexure in such a manner that the applied moments produce curvature of the sandwich facing planes. Also, in this regard, core shear ultimate stress $\left(\mathrm{F}_{\mathrm{s}}{ }^{\mathrm{ult}}\right)$, facing bending stress $(\sigma)$, transverse shear rigidity $(\mathrm{U})$ and core shear modulus $(\mathrm{G})$ of introduced sandwich panel are calculated based on ASTM C393/C393M (ASTM-C393/C393M, 2011) and ASTM D7250/D7250M (ASTM-D7250/D7250M, 2011) using six medium-scale sandwich specimens with $45 \mathrm{~cm}$ length, $20 \mathrm{~cm}$ width and $10 \mathrm{~cm}$ as total thickness of composite section. The detailed descriptions of the tests carried out on specimens which are four-point quarter-span loading and three-point mid-span loading flexural tests (Fig. 7) are discussed in this section.
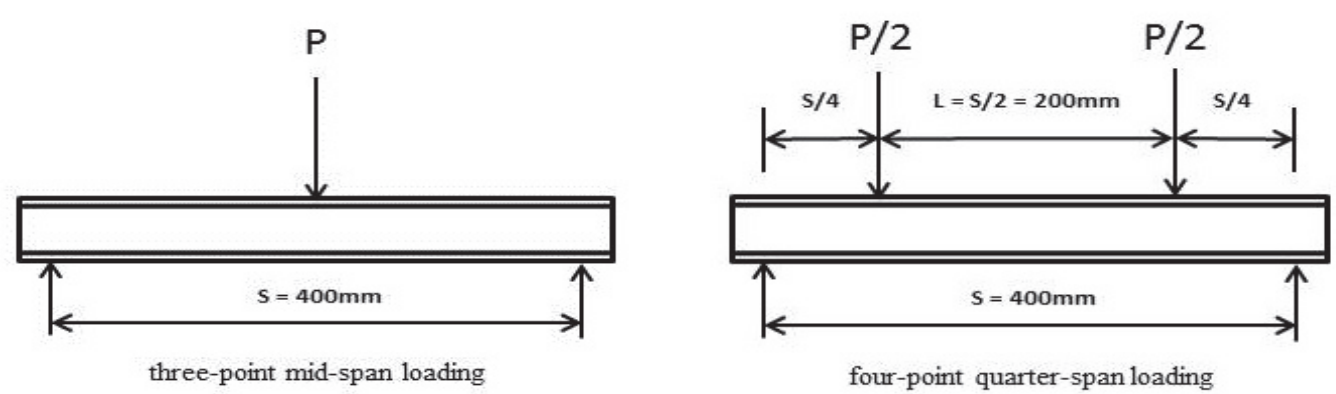

Fig. 7. Four-point quarter loading and three-point mid span loading configurations

The four-point bending test in accordance with ASTM C393/C393M under quarter point loading configuration is performed for core shear ultimate stress $\left(\mathrm{F}_{\mathrm{s}}\right.$ ult $)$ and facing bending stress $(\sigma)$ calculations. This test method is limited to obtaining the core shear strength or core-to-facing shear strength, and to obtaining load-deflection data for use in calculating sandwich beam flexural and shear stiffness using practice D7250/D7250M. The test setup is illustrated in Fig. 8(a). An INSTRON test machine (model no. 5500R) was used. High resistance rubber pads (with a Shore A durometer hardness of 60 , a nominal width of $25 \mathrm{~mm}$ and a nominal thickness of $3 \mathrm{~mm}$ ) were inserted at the loading and supporting points to distribute the load uniformly and reduce the stress concentrations. Three specimens were investigated, where they were tested in one-way bending with the span of $400 \mathrm{~mm}$, under two equal point loads, applied at $100 \mathrm{~mm}$ from each support. The specimens have been inserted into the test fixture and then were aligned so that the longitudinal axis of the specimen was perpendicular (within $1^{\circ}$ ) to the longitudinal axes of the loading bars, and the bars were parallel (within $1^{\circ}$ ) to the plane of the specimen facings. The specimens were loaded to failure at a displacement rate of $6 \mathrm{~mm} / \mathrm{min}$. The bottom deflection at mid-span was recorded using a Linear Potentiometer (LP) having a minimum accuracy of $+/-1 \%$. A data acquisition system was used to record the load, displacement, and deflection during testing. In this study applied force versus crosshead displacement, and applied force versus deflection data were recorded continuously. In addition, the visual method was used to determine any initial failure (Fig. 8 (b)). 


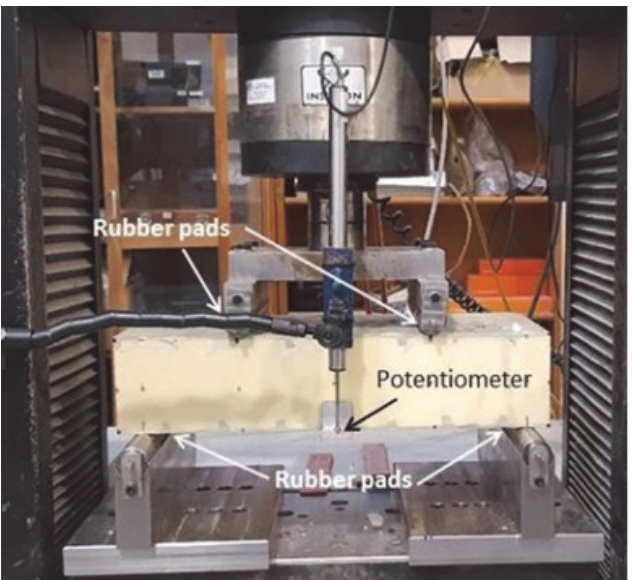

(a)

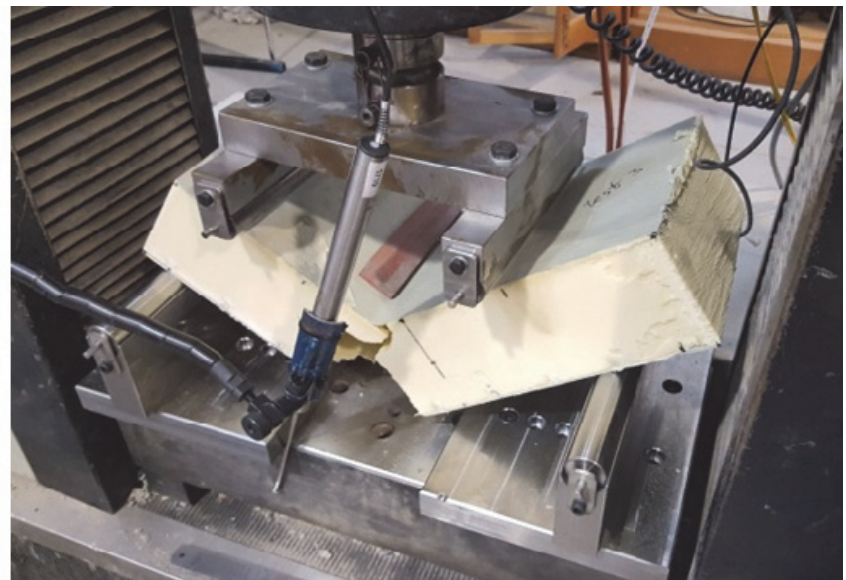

(b)

Fig. 8. (a) Four-point quarter-span loading flexural test setup; and (b) multi-mode of failure in the vicinity of the midspan

The applied force versus crosshead displacement and mid-span deflection are shown in Figs. 9 and 10, respectively.

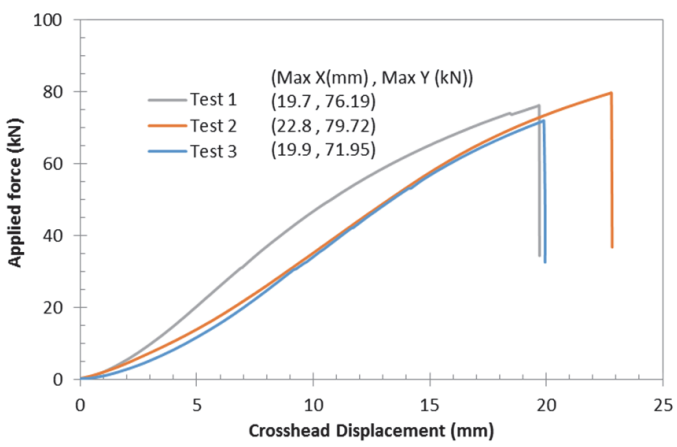

Fig. 9. The applied force versus crosshead displacement for four-point quarter-span loading test

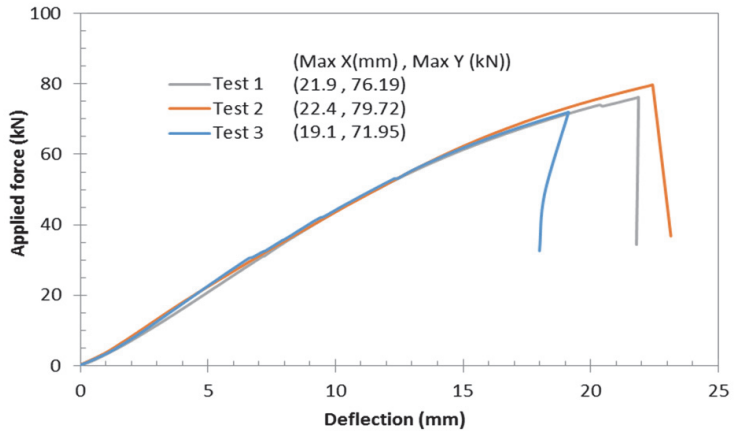

Fig. 10. The applied force versus mid-span deflection for four-point quarter-span loading flexural test

\section{Calculation of core shear ultimate stress and facing bending stress}

In this section, shear ultimate stress $\left(\mathrm{F}_{\mathrm{s}}{ }^{\mathrm{ult}}\right)$ and facing bending stress $(\sigma)$ of innovated sandwich panel are calculated using the typical cross section shown in Fig. 11; parameters and formulas based on ASTM C393/C393M.

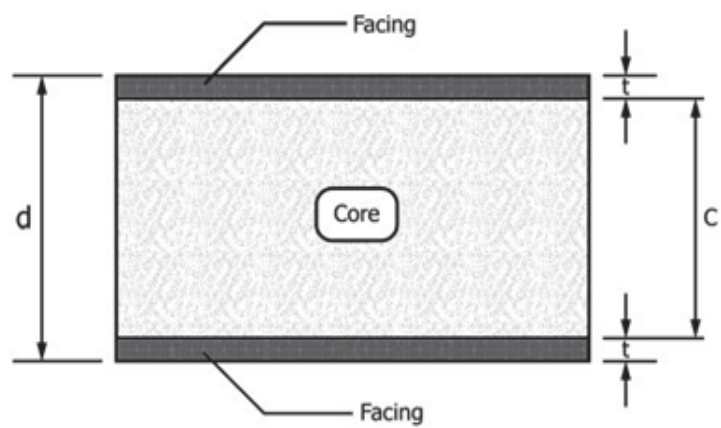

$$
\begin{aligned}
& \mathrm{F}_{\mathrm{s}}{ }^{\text {ult }}=\text { core shear ultimate stress }=\mathrm{P}_{\max } /(\mathrm{d}+\mathrm{c}) \mathrm{b} \quad(\mathrm{MPa}) \\
& \sigma=\text { facing bending stress }=\mathrm{PS} /[4 \mathrm{t}(\mathrm{d}+\mathrm{c}) \mathrm{b}] \quad(\mathrm{MPa})
\end{aligned}
$$

Where:

$\mathrm{P}_{\max }=$ maximum force carried by test specimen before failure $(\mathrm{N})$

$\mathrm{b}=$ sandwich specimen width $(\mathrm{mm})$

$\mathrm{d}=$ sandwich total thickness $(\mathrm{mm})$

$\mathrm{c}=$ core thickness $(\mathrm{mm})$

$\mathrm{t}=$ facing thickness $(\mathrm{mm})$

Fig. 11. Sandwich panel thickness dimensions (ASTM-C393/C393M, 2011) 
The results and calculation of core shear ultimate stress and facing bending stress are summarized in Table 4.

Table 4. Calculation of core shear ultimate stress and facing bending stress of innovated sandwich panel

\begin{tabular}{ccccc}
\hline & $\begin{array}{c}\mathrm{P}_{\max } \\
(\mathrm{kN})\end{array}$ & $\begin{array}{c}\mathrm{F}_{\mathrm{s}}{ }_{\mathrm{s}} \\
(\mathrm{MPa})\end{array}$ & $\begin{array}{c}\sigma \\
(\mathrm{MPa})\end{array}$ & Failure mode and location* \\
\hline Specimen 1 & 76.19 & 1.9 & 97.2 & $(\mathrm{M})(\mathrm{G})(\mathrm{B} / \mathrm{C})$ \\
Specimen 2 & 79.72 & 2 & 101.7 & $(\mathrm{M})(\mathrm{G})(\mathrm{B} / \mathrm{C})$ \\
Specimen 3 & 71.95 & 1.8 & 91.8 & $(\mathrm{M})(\mathrm{G})(\mathrm{B} / \mathrm{C})$ \\
\hline Average & 75.95 & 1.9 & 96.9 & \\
Standard deviation & 3.89 & 0.1 & 5 & \\
CV $(\%)$ & 5.12 & 5.2 & 5.2 & $(\mathrm{~B} / \mathrm{C})$ \\
\hline$*(\mathrm{M})(\mathrm{G})(\mathrm{B} / \mathrm{C}):($ Multi-mode $) /($ Gage $) /($ Bottom facing/Core $)($ ASTM-C393/C393M, 2011).
\end{tabular}

The facing bending stress is calculated as a reference value at the maximum applied force. Since this test method is restricted to the core or core-to-facing shear failures, the facing stress does not represent the facing ultimate strength. To obtain the facing ultimate strength, the test method ASTM D7249/D7249M can be used (ASTM-D7249/D7249M, 2017). The results show that the foam core in composite section, withstand twice shear stress as the bare foam material.

\section{Calculation of transverse shear rigidity and core shear modulus}

Transverse shear rigidity $(\mathrm{U})$ and core shear modulus $(\mathrm{G})$ of innovated sandwich panel can be calculated based on the results of the four-point quarter-span loading tests and a series of similar threepoint mid-span loading supplementary tests based on ASTM D7250/D7250M. The formulations for calculating are presented in Table 5 (ASTM-D7250/D7250M, 2011).

Table 5. Transverse shear rigidity and core shear modulus based on ASTM standards

\begin{tabular}{|c|c|c|}
\hline Loading Configuration & $\begin{array}{c}\mathrm{U} \\
\text { (Transverse shear rigidity) }\end{array}$ & $\begin{array}{c}\mathbf{G} \\
\text { (Core shear modulus) }\end{array}$ \\
\hline $\begin{array}{c}\text { One D7249/D7249M Standard 4-Point Loading } \\
\text { and } \\
\text { One 3-Point Mid-Span Loading }\end{array}$ & $\begin{array}{c}9 \mathrm{P}_{1} \mathrm{~S}_{1}\left(141 \mathrm{~S}_{1}^{2} / \mathrm{S}_{2}^{2}-121\right) \\
/ 4 \Delta_{1}\left(1269\left(\mathrm{P}_{1} \mathrm{~S}_{1}^{3} \Delta_{2} / \mathrm{P}_{2} \mathrm{~S}_{2}{ }^{3} \Delta_{1}\right)-1331\right)\end{array}$ & $\mathrm{U}(\mathrm{d}-2 \mathrm{t}) /\left[(\mathrm{d}-\mathrm{t})^{2} \mathrm{~b}\right]$ \\
\hline $\begin{array}{c}\text { One D7249/D7249M Standard 4-Point Loading } \\
\text { and } \\
\text { One 4-Point Third-Span Loading }\end{array}$ & $\begin{array}{c}9 \mathrm{P}_{1} \mathrm{~S}_{1}\left(2538 \mathrm{~S}_{1}^{2} / \mathrm{S}_{2}^{2}-2783\right) \\
/ 4 \Delta_{1}\left(34263\left(\mathrm{P}_{1} \mathrm{~S}_{1}^{3} \Delta_{2} / \mathrm{P}_{2} \mathrm{~S}_{2}{ }^{3} \Delta_{1}\right)-30613\right)\end{array}$ & $U(d-2 t) /\left[(d-t)^{2} b\right]$ \\
\hline $\begin{array}{l}\text { One D7249/D7249M Standard 4-Point Loading } \\
\text { and } \\
\text { One 4-Point Quarter-Span Loading }\end{array}$ & $\begin{array}{c}9 \mathrm{P}_{1} \mathrm{~S}_{1}\left(1128 \mathrm{~S}_{1}^{2} / \mathrm{S}_{2}^{2}-1331\right) \\
/ 4 \Delta_{1}\left(20304\left(\mathrm{P}_{1} \mathrm{~S}_{1}^{3} \Delta_{2} / \mathrm{P}_{2} \mathrm{~S}_{2}{ }^{3} \Delta_{1}\right)-14641\right)\end{array}$ & $\mathrm{U}(\mathrm{d}-2 \mathrm{t}) /\left[(\mathrm{d}-\mathrm{t})^{2} \mathrm{~b}\right]$ \\
\hline $\begin{array}{c}\text { One 3-Point Mid-Span Loading } \\
\text { and } \\
\text { One 4-Point Quarter-Span Loading }\end{array}$ & $\begin{array}{c}\mathrm{P}_{1} \mathrm{~S}_{1}\left(8 \mathrm{~S}_{1}^{2} / 11 \mathrm{~S}_{2}^{2}-1\right) \\
/ 4 \Delta_{1}\left(\left(16 \mathrm{P}_{1} \mathrm{~S}_{1}^{3} \Delta_{2} / 11 \mathrm{P}_{2} \mathrm{~S}_{2}^{3} \Delta_{1}\right)-1\right)\end{array}$ & $U(d-2 t) /\left[(d-t)^{2} b\right]$ \\
\hline $\begin{array}{c}\text { One 3-Point Mid-Span Loading } \\
\text { and } \\
\text { One 4-Point Third-Span Loading }\end{array}$ & $\begin{array}{c}\mathrm{P}_{1} \mathrm{~S}_{1}\left(18 \mathrm{~S}_{1}^{2} / 23 \mathrm{~S}_{2}^{2}-1\right) \\
/ 4 \Delta_{1}\left(\left(27 \mathrm{P}_{1} \mathrm{~S}_{1}^{3} \Delta_{2} / 23 \mathrm{P}_{2} \mathrm{~S}_{2}^{3} \Delta_{1}\right)-1\right)\end{array}$ & $\mathrm{U}(\mathrm{d}-2 \mathrm{t}) /\left[(\mathrm{d}-\mathrm{t})^{2} \mathrm{~b}\right]$ \\
\hline $\begin{array}{c}\text { One 4-Point Quarter-Span Loading } \\
\text { and } \\
\text { One 4-Point Third-Span Loading }\end{array}$ & $\begin{array}{c}\mathrm{P}_{1} \mathrm{~S}_{1}\left(99 \mathrm{~S}_{1}^{2} / 92 \mathrm{~S}_{2}^{2}-1\right) \\
/ 2 \Delta_{1}\left(\left(297 \mathrm{P}_{1} \mathrm{~S}_{1}^{3} \Delta_{2} / 368 \mathrm{P}_{2} \mathrm{~S}_{2}^{3} \Delta_{1}\right)-1\right)\end{array}$ & $\mathrm{U}(\mathrm{d}-2 \mathrm{t}) /\left[(\mathrm{d}-\mathrm{t})^{2} \mathrm{~b}\right]$ \\
\hline Two 3-Point Mid-Span Loading & $\begin{array}{c}\mathrm{P}_{1} \mathrm{~S}_{1}\left(\mathrm{~S}_{1}^{2} / \mathrm{S}_{2}^{2}-1\right) \\
/ 4 \Delta_{1}\left(\left(\mathrm{P}_{1} \mathrm{~S}_{1}^{3} \Delta_{2} / \mathrm{P}_{2} \mathrm{~S}_{2}^{3} \Delta_{1}\right)-1\right)\end{array}$ & $\mathrm{U}(\mathrm{d}-2 \mathrm{t}) /\left[(\mathrm{d}-\mathrm{t})^{2} \mathrm{~b}\right]$ \\
\hline $\mathrm{U}=$ transverse shear rigidity $(\mathrm{N})$ & $\mathrm{P}_{1}=$ applied force for configuration $\# 1(\mathrm{~N})$ & \\
\hline $\mathrm{G}=$ core shear modulus $(\mathrm{MPa})$ & $\mathrm{P}_{2}=$ applied force for configuration $\# 2(\mathrm{~N})$ & \\
\hline $\begin{array}{l}\Delta_{1}=\text { beam mid-span deflection for configuration \#1 } \\
\text { corresponding to force } \mathrm{P} 1(\mathrm{~mm})\end{array}$ & $\begin{array}{l}\mathrm{S}_{1}=\text { length of support span for configuration } \# 1 \\
(\mathrm{~mm})\end{array}$ & \\
\hline $\begin{array}{l}\Delta_{2}=\text { beam mid-span deflection for configuration } \# 2 \\
\text { corresponding to force } \mathrm{P} 2(\mathrm{~mm})\end{array}$ & $\begin{array}{l}\mathrm{S}_{2}=\text { length of support span for configuration } \# 2 \\
(\mathrm{~mm})\end{array}$ & \\
\hline
\end{tabular}

According to ASTM D7250/D7250M transverse shear rigidity are calculated based on ten loaddeflection selective steps of the least maximum applied force regarding both loading configurations (Tables 6 and Fig. 12). 
Table 6. The least maximum applied forces and their related mid-span deflections.

\begin{tabular}{ccccc}
\hline & 4-Point Quarter & Span Loading & \multicolumn{3}{c}{ 3-Point Mid Span } & Loading \\
\cline { 2 - 5 } & $\mathrm{P}_{\max }$ & $\Delta_{\operatorname{midspan}}$ & $\mathrm{P}_{\max }$ & $\Delta_{\operatorname{midspan}}$ \\
\hline Specimen 1 & 76.19 & 21.9 & 56.23 & 24.9 \\
Specimen 2 & 79.72 & 22.4 & 52.54 (minimum) & 23.8 \\
Specimen 3 & 71.95 (minimum) & 19.1 & 53.98 & 24.2 \\
\hline Average & 75.95 & 21.1 & 54.25 & 1.86 \\
Standard deviation & 3.89 & 1.8 & 3.5 & 0.56 \\
CV (\%) & 5.12 & 8.42 & 2.3 \\
\hline
\end{tabular}
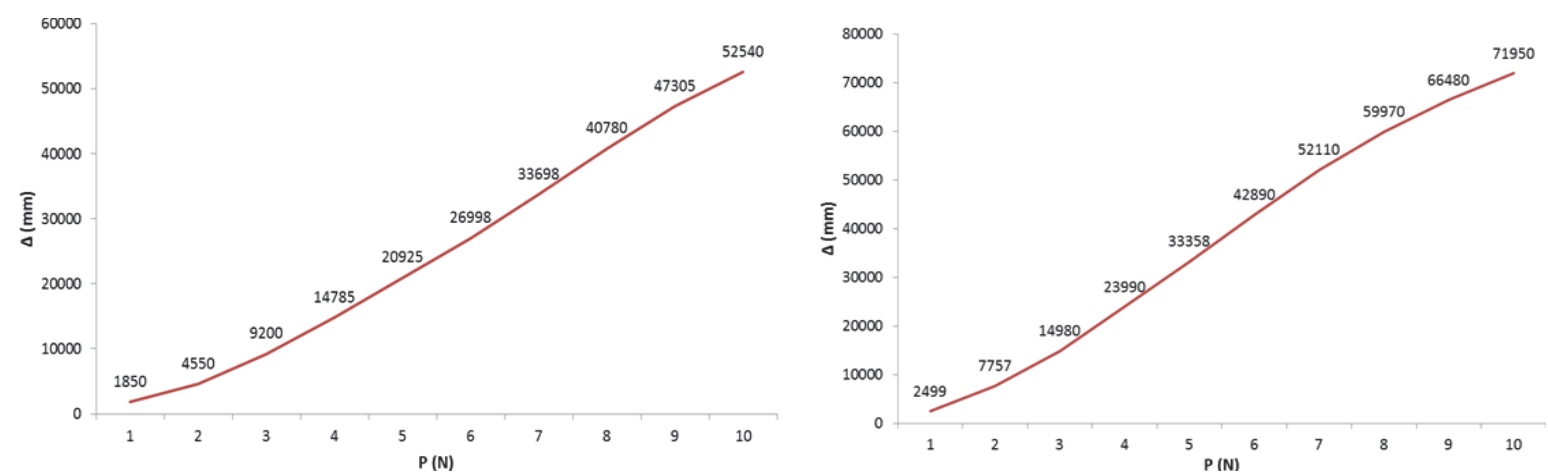

Fig. 12. Selected load-displacement levels of four-point quarter (right) and three-point mid span (left) loading configurations

The results and calculation of transverse shear rigidity and core shear modulus are summarized in Tables 7.

Table 7. Transverse shear rigidity (U) and core shear modulus calculations (G)

\begin{tabular}{ccccccccc}
\hline & $\begin{array}{c}\text { 3-Point } \\
\mathrm{P}_{1}(\mathrm{~N})\end{array}$ & $\begin{array}{c}\text { Mid Span } \\
\Delta_{1}(\mathrm{~mm})\end{array}$ & $\begin{array}{c}\text { Loading } \\
\mathrm{S}_{1}(\mathrm{~mm})\end{array}$ & $\begin{array}{c}\text { 4-Point } \\
\mathrm{P}_{2}(\mathrm{~N})\end{array}$ & $\begin{array}{c}\text { Quarter Span } \\
\Delta_{2}(\mathrm{~mm})\end{array}$ & $\begin{array}{c}\text { Loading } \\
\mathrm{S}_{2}(\mathrm{~mm})\end{array}$ & UsteP (N) & GSTEP (MPa) \\
\hline Step 1 (adjusting) & 1850 & 1.2 & 400 & 2499 & 0.8 & 400 & adjusting & adjusting \\
Step 2 & 4550 & 2.5 & 400 & 7757 & 2 & 400 & 88500 & 4.4 \\
Step 3 & 9200 & 4.6 & 400 & 14980 & 3.5 & 400 & 98000 & 4.9 \\
Step 4 & 14785 & 6.9 & 400 & 23990 & 5.3 & 400 & 147600 & 7.4 \\
Step 5 & 19925 & 9.1 & 400 & 33358 & 7.4 & 400 & 205300 & 10.3 \\
Step 6 & 25648 & 11.9 & 400 & 42890 & 9.7 & 400 & 203900 & 10.2 \\
Step 7 & 31698 & 14.5 & 400 & 52110 & 12 & 400 & 225000 & 11.2 \\
Step 8 & 37180 & 16.9 & 400 & 59970 & 14.4 & 400 & 262300 & 13.1 \\
Step 9 & 44305 & 20.1 & 400 & 66480 & 16.7 & 400 & 383500 & 19.2 \\
Step 10 (main) & 52540 & 23.8 & 400 & 71950 & 19.1 & 400 & 417000 & 20.8 \\
\hline Average over time & & & & & & 25700 & 11.3 \\
\hline
\end{tabular}

\section{Numerical investigation}

Numerical simulations were carried out to find the non-linear behaviour of the sandwich panel and compare with the experimental measurements of the flexural behaviour of the composite sandwich beams. The simulations of the four-point static bending test of the composite sandwich, the FE modelling was performed using ANSYS R15 where a quasi-static three-dimensional model has been developed to simulate and predict the mechanical performance of the composite sandwich panel under bending. For FE modelling, the same dimensions, and the same loading rate $(6 \mathrm{~mm} / \mathrm{min})$ were considered as for the experimental program. The PU foam was meshed using Hexahedral dominant, Quadrilateral and Triangular meshing. The HDPE sheets were meshed using Multizone Hexahedral/prism with Quadrilateral and Triangular elements while the studs meshed using hexahedral elements (Sharafi, et al. 2015, 2017a, 2017b). The mechanical properties of the PU foam and the HDPE sheets, obtained from experiments, were used for calibrating the inputs. 


\subsection{Flexural behaviour}

The FE results show equivalent (Von-Mises) stress of foam has been concentrated at two strips between loading effect points and supports and other areas are under very low stress. The first yielding symptom of foam occurs when the equivalent (Von-Mises) stress of foam reaches to manufacture minimum identified yielding stress $(2.8 \mathrm{MPa})$. However, the real yielding stress occurs at $3.51 \mathrm{MPa}$. Fig. 13 shows Von-Mises stress-strain diagram of foam.

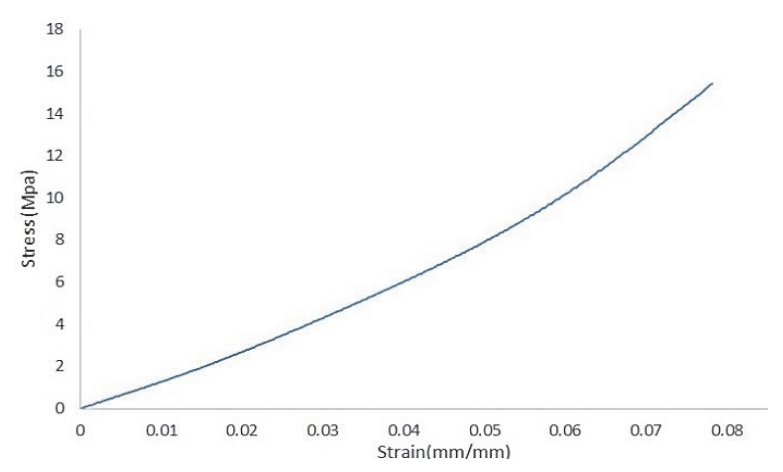

Fig. 13. Equivalent (Von-Mises) stress - strain diagram of foam

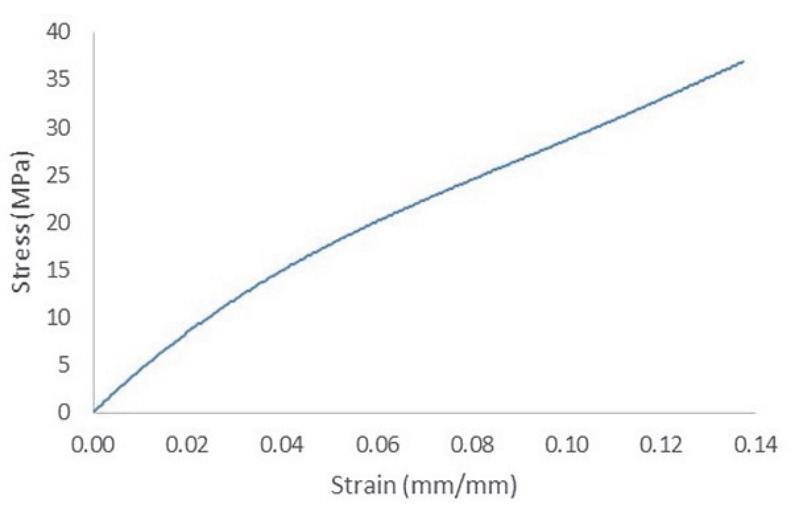

Fig. 14. Equivalent (Von-Mises) stress - strain diagram of Studliner

With regard to the skins, by applying more pressure, equivalent (Von-Mises) stress of Studliner reaches to yielding stress, where the maximum strain of Studliner is $0.048 \mathrm{~mm} / \mathrm{mm}$. Maximum equivalent stress appears at the edges of Studliner. In addition, shear stress at studs keeps increasing as the applied load continues increasing. Fig. 14 shows Von-Mises stress-strain diagram of the skins. Then, as similar as experimental tests, at $60^{\text {th }}$ second the model start to collapse and large deformation, debonding and demolition between foam and skins appear on the loading point until 70th second (Figs. 15 - 18).
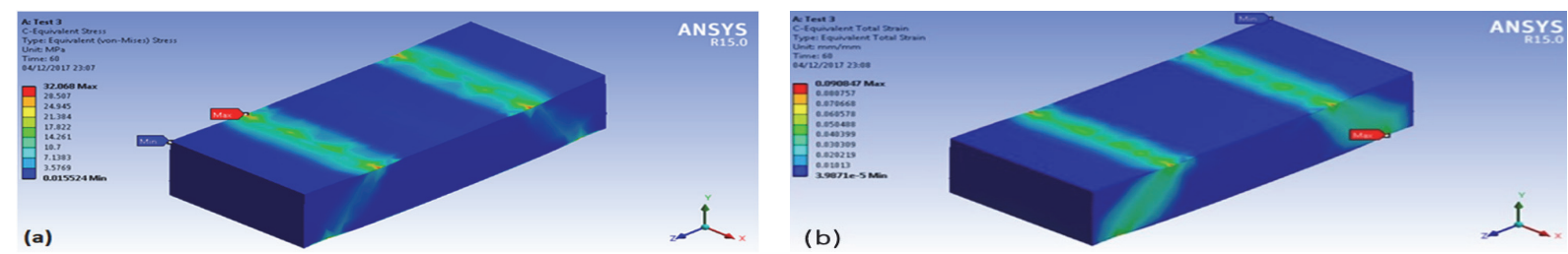

Fig. 15. (a) Stress and (b) strain of composite panel at collapsing mode

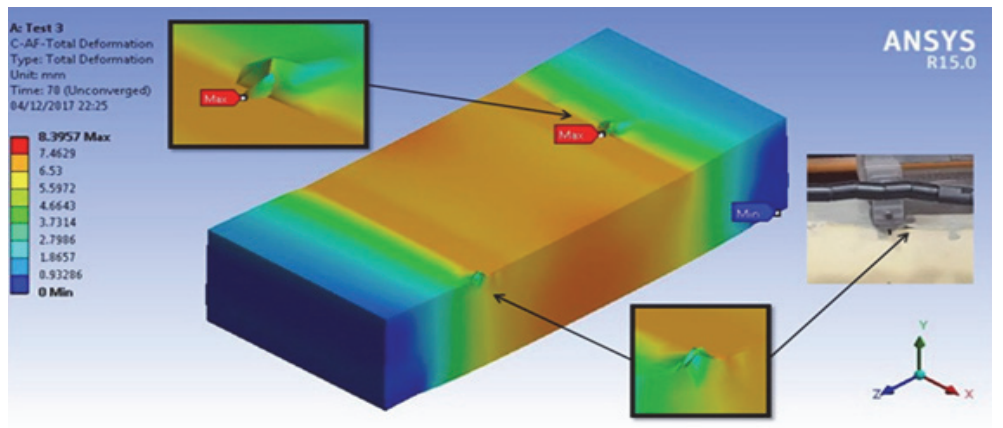

Fig. 16. Large deformation and debonding between the skin and foam core at collapsing mode 


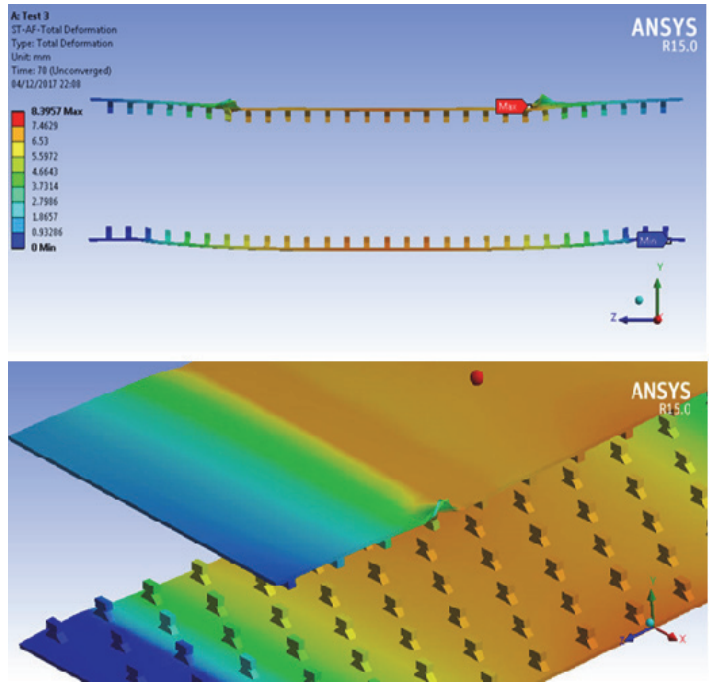

Fig. 17. Large deformation and debonding of Studliner at collapsing mode

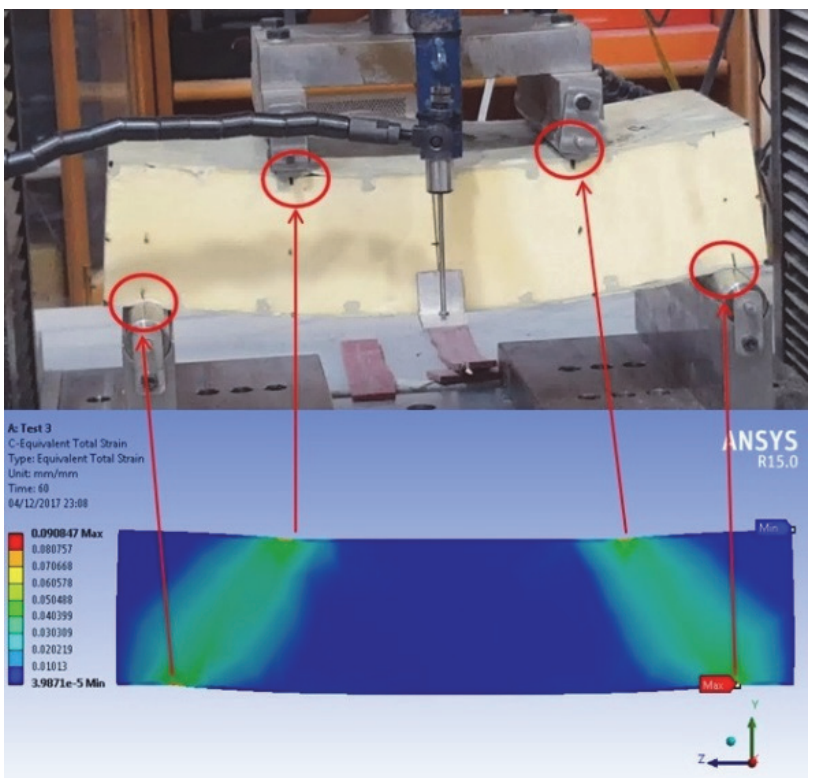

Fig. 18. Large deformation and maximum strain of composite panel just before collapse

By applying more pressure to the specimens, the ultimate fracture occurs on the mid-span at the maximum deflection point. The fracture profile is shown in Fig. 19.

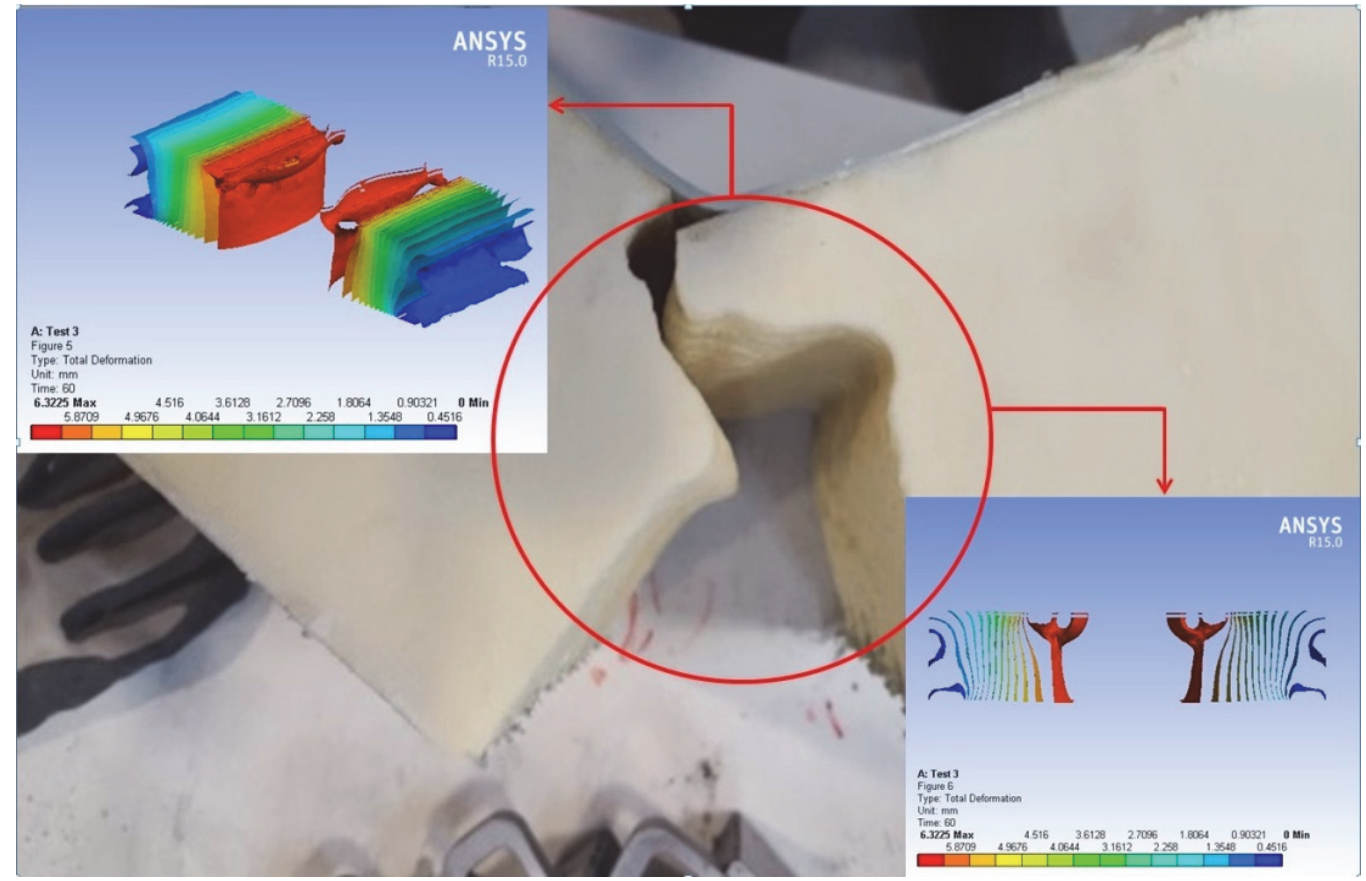

Fig. 19. The fracture profile and maximum deflection at mid-span of composite panel.

Fig. 20 shows maximum Von-Mises stress-strain diagram of the composite panel. As it can be seen, in elastic range (as strain $<2 \%$ ) the composite panel has a semi linear demeanour but, after yielding point shows a hyper elastic behaviour. 


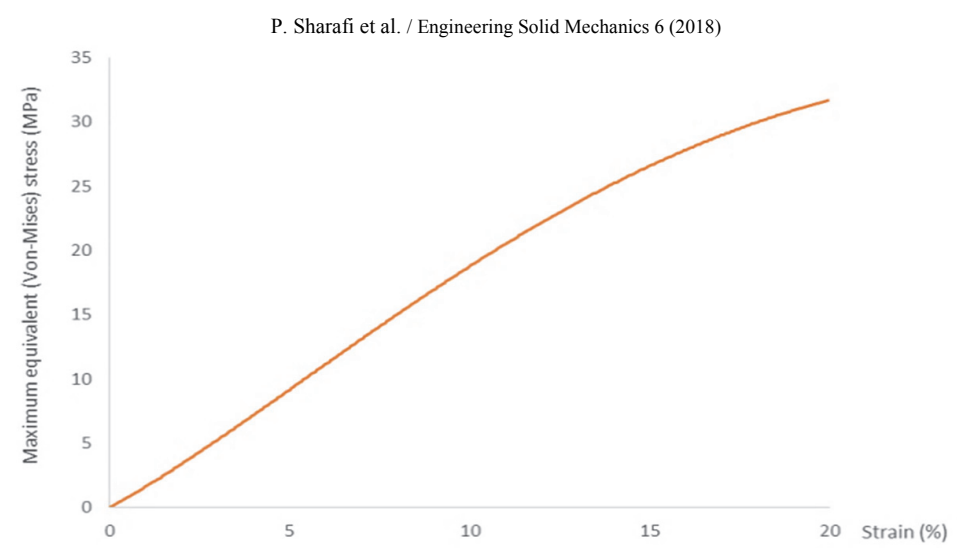

Fig. 20. Equivalent (Von-Mises) maximum stress - strain diagram of composite panel

Results indicate that under flexure, the foam core and skins displacement are in sync, which demonstrate well integrated behaviour of the introduced composite panel, as shown in Fig. 21 and Fig. 22 .

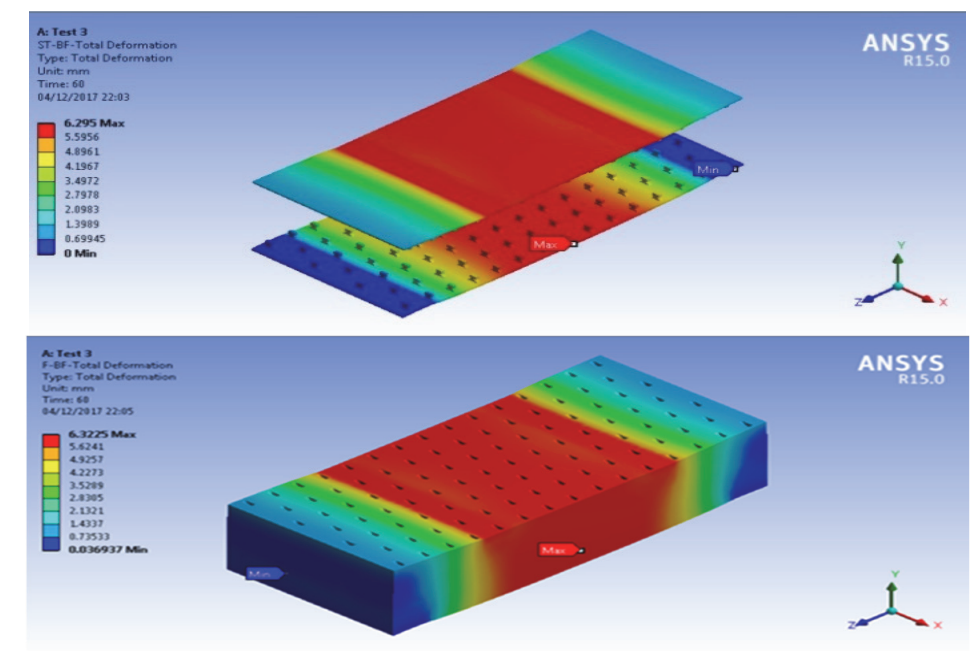

Fig. 21. Homologous deflection of Studliner skins and foam core

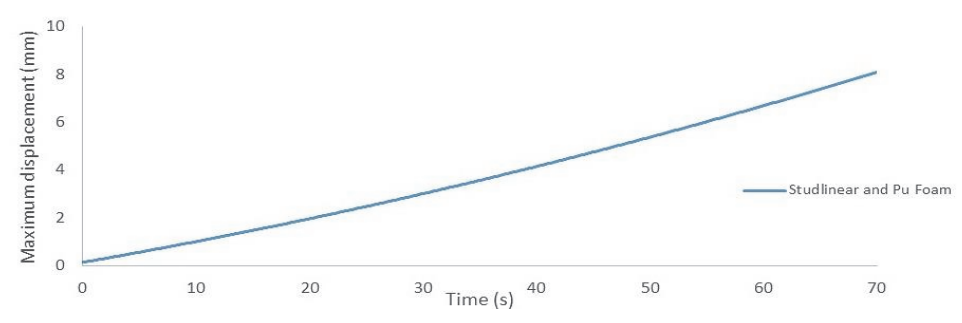

Fig. 22. Sync behaviour of maximum mid-span displacement of the skin and foam in time

\subsection{Shear Behaviour}

XY component of shear stress has a uniform distribution on the skin and core, which demonstrates the good performance of skin studs in shear transfer. When the XY component of shear stress reaches to yielding point at both of core and skin, maximum XY shear component occurs at edges of the skin and core, under loading point. In addition, there is not any shear concentration in the skin studs on XY plane. YZ component of shear stress has a uniform distribution on the skin and core. This component has a strip of concentration at the loading line on the surface of the core as well as surface and body of the foam core. These strips continue toward supports in foam core. The YZ component of shear stress 
reaches to yielding point at both the core and skin, where there is not any shear concentration at studs of skin on the YZ plane.

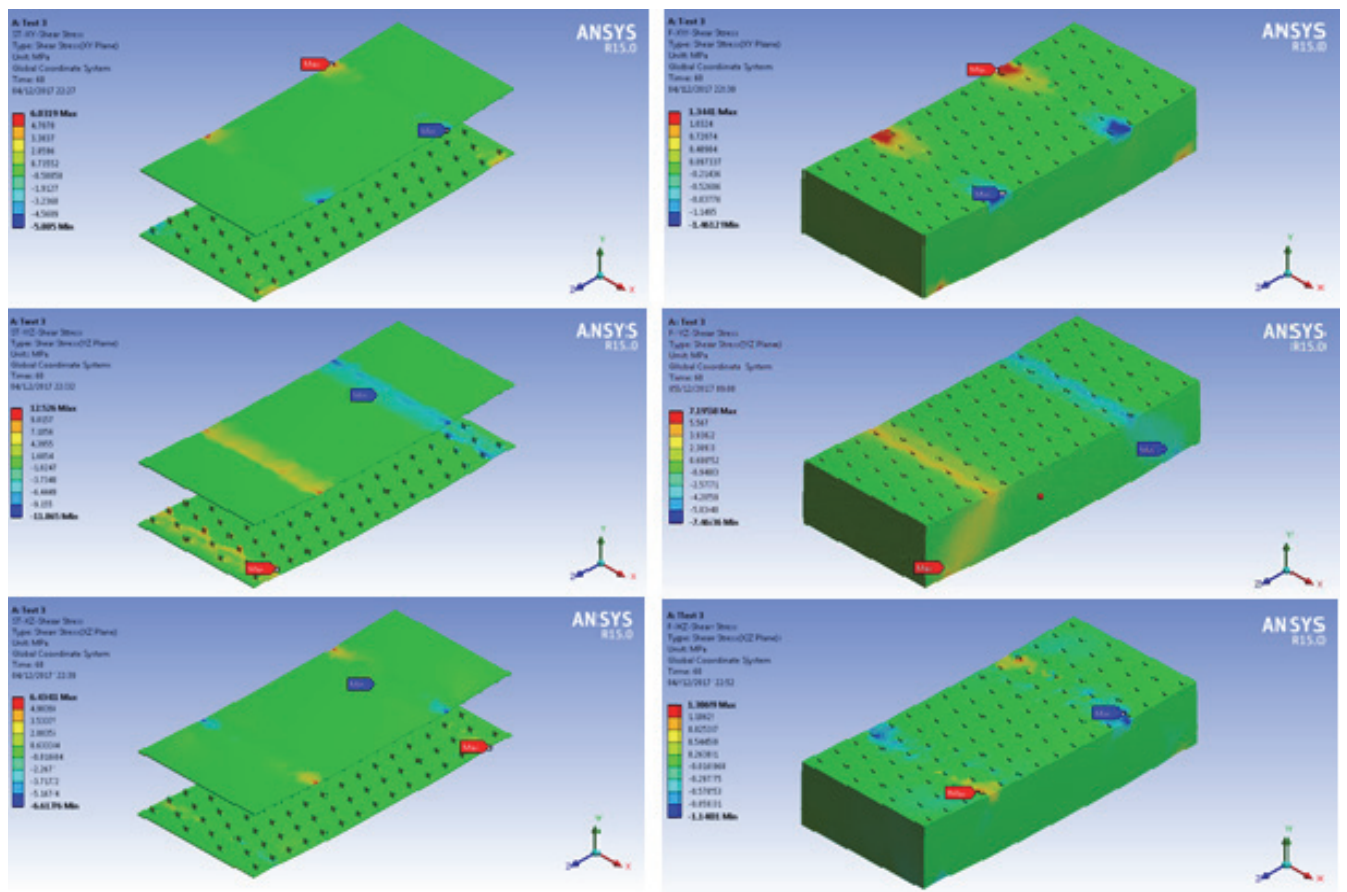

Fig. 23. Distribution of component of shear stress on the skin and foam core at collapsing mode

The distribution of $\mathrm{XZ}$ component of shear stress on the skin is as similar as XY component. The distribution of this component on studs is completely uniform. Maximum XZ shear component occurs at the edges of skin. The XZ component of shear stress on the core has some local concentration and at other areas has a very low intensity. The XZ component of shear stress reaches to yielding point at both of foam and the skin. These distributions are illustrated in Fig. 23. As shown in Fig. 24, results indicate that the XY component of shear stress show relatively linear behaviour at low strains $(<2 \%)$ and nonlinear behaviour at higher amounts. The diagram of $\mathrm{YZ}$ component of shear stress-strain is linear. In addition, the XY component of shear stress show nonlinearity with a positive slope until collapsing mode.

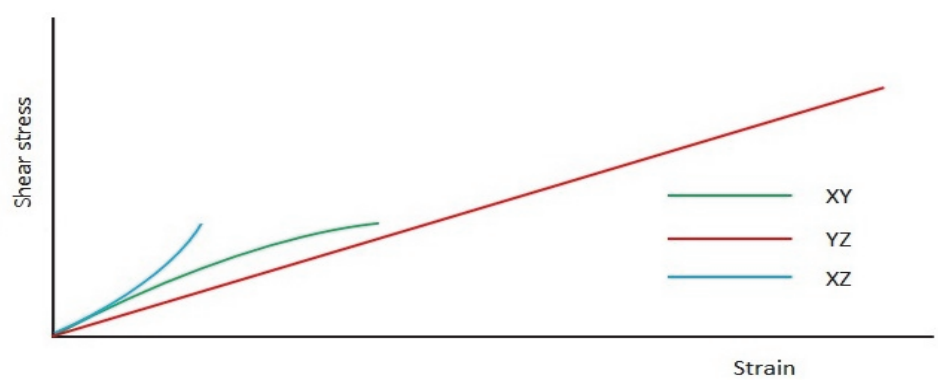

Fig. 24. Schematic stress-strain diagrams of $X Y, Y Z$ and $X Z$ component of shear at composite panel

\section{Conclusion}

Foam filled sandwich panels are one of the most popular and widely investigated types of composite structures. In this study an innovative sandwich panel comprising 3D-HDPE skin layers and a highdensity foam core was proposed and the flexural and shear behaviour was investigated by experimental and numerical research. The results showed that using 3D skins with 1200 studs per square meter, the 
composite sandwich panels resulted in a strong and stable composite section than individual sandwich sections alone. Results of the quasi-static three-dimensional model and the material nonlinear simulations of the sandwich panels also indicate that under flexure, the foam core and skins displacement are in sync, which demonstrate well integrated and ductile behaviour of the introduced composite panel.

\section{References}

Allen, H. G. (2013). Analysis and design of structural sandwich panels: the commonwealth and international library: structures and solid body mechanics division. Elsevier.

Aliha, M. R. M., Linul, E., Bahmani, A., \& Marsavina, L. (2018). Experimental and theoretical fracture toughness investigation of PUR foams under mixed mode I+ III loading. Polymer Testing, 67,7583.

ASTM, D., 1621-00. Standard Test Method for Compressive Properties of Rigid Cellular Plastics.

ASTM-C393/C393M, Standard Test Method for Core Shear Properties of Sandwich Constructions by Beam Flexure. 2011.

ASTM-D6693, Standard Test Method for Determining Tensile Properties of Nonreinforced Polyethylene and Nonreinforced Flexible Polypropylene Geomembranes, in ASTM International. 2015: West Conshohocken, PA.

ASTM-D7249/D7249M, Standard Test Method for Facing Properties of Sandwich Constructions by Long Beam Flexure. 2017.

ASTM-D7250/D7250M, Standard Practice for Determining Sandwich Beam Flexural and Shear Stiffness. 2011.

ASTM-E1730, Standard Specification for Rigid Foam for Use in Structural Sandwich Panel Core, in ASTM International. 2015: West Conshohocken, PA.

Carlsson, L. A., \& Kardomateas, G. A. (2011). Structural and failure mechanics of sandwich composites (Vol. 121). Springer Science \& Business Media.

Correia, J. R., Garrido, M., Gonilha, J. A., Branco, F. A., \& Reis, L. G. (2012). GFRP sandwich panels with PU foam and PP honeycomb cores for civil engineering structural applications: effects of introducing strengthening ribs. International Journal of Structural Integrity, 3(2), 127-147.

Dawood, M., Taylor, E., \& Rizkalla, S. (2010). Two-way bending behavior of 3-D GFRP sandwich panels with through-thickness fiber insertions. Composite Structures, 92(4), 950-963.

Fam, A., \& Sharaf, T. (2010). Flexural performance of sandwich panels comprising polyurethane core and GFRP skins and ribs of various configurations. Composite Structures, 92(12), 2927-2935.

Garrido, M., Correia, J. R., \& Keller, T. (2016). Effect of service temperature on the shear creep response of rigid polyurethane foam used in composite sandwich floor panels. Construction and Building Materials, 118, 235-244.

Hayes, M. D. (2003). Structural analysis of a pultruded composite beam: shear stiffness determination and strength and fatigue life predictions (Doctoral dissertation, Virginia Tech).

Kumar, M. V., \& Soragaon, B. (2014). Fabrication and evaluation of multilayered polyurethane foam core sandwich panels for static flexural stiffness. Procedia Engineering, 97, 1227-1236.

Lv, L., Huang, Y., Cui, J., Qian, Y., Ye, F., \& Zhao, Y. (2017). Bending properties of three-dimensional honeycomb sandwich structure composites: experiment and Finite Element Method simulation. Textile Research Journal, 0040517517703602.

Manalo, A. (2013). Structural behaviour of a prefabricated composite wall system made from rigid polyurethane foam and Magnesium Oxide board. Construction and Building Materials, 41, 642653.

Marsavina, L., Constantinescu, D. M., Linul, E., Voiconi, T., Apostol, D. A., \& Sadowski, T. (2014). Evaluation of mixed mode fracture for PUR foams. Procedia Materials Science, 3, 1342-1352.

Marsavina, L., Linul, E., Voiconi, T., \& Sadowski, T. (2013). A comparison between dynamic and static fracture toughness of polyurethane foams. Polymer Testing, 32(4), 673-680.

Mostafa, A. (2015). Numerical analysis on the effect of shear keys pitch on the shear performance of foamed sandwich panels. Engineering Structures, 101, 216-232. 
Mostafa, A., Shankar, K., \& Morozov, E. V. (2015). Behaviour of PU-foam/glass-fibre composite sandwich panels under flexural static load. Materials and Structures, 48(5), 1545-1559.

Mostafa, A., Shankar, K., \& Morozov, E. V. (2015). Independent analytical technique for analysis of the flexural behaviour of the composite sandwich panels incorporated with shear keys concept. Materials and Structures, 48(8), 2455-2474.

Potluri, P. A., Kusak, E., \& Reddy, T. Y. (2003). Novel stitch-bonded sandwich composite structures. Composite Structures, 59(2), 251-259.

Reis, E. M., \& Rizkalla, S. H. (2008). Material characteristics of 3-D FRP sandwich panels. Construction and Building Materials, 22(6), 1009-1018.

Sharaf, T. (2010). Flexural behaviour of sandwich panels Composed of polyurethane core and GFRP skins and ribs(Doctoral dissertation).

Sharaf, T., \& Fam, A. (2010). Experimental investigation of large-scale cladding sandwich panels under out-of-plane transverse loading for building applications. Journal of Composites for Construction, 15(3), 422-430.

Sharaf, T., \& Fam, A. (2012). Numerical modelling of sandwich panels with soft core and different rib configurations. Journal of Reinforced Plastics and Composites, 31(11), 771-784.

Sharaf, T., Shawkat, W., \& Fam, A. (2010). Structural performance of sandwich wall panels with different foam core densities in one-way bending. Journal of Composite Materials, 44(19), 22492263.

Sharafi, P., Hadi, M.N., The, L. (2014b). Geometric design optimization for dynamic response problems of continuous reinforced concrete beams. Journal of Computing in Civil Engineering, 28(2), 202-209.

Sharafi, P., Hadi, M., \& Teh, L. (2012a). Optimum Spans' Lengths of Multi-span Reinforced Concrete Beams Under Dynamic Loading. In: Caicedo J., Catbas F., Cunha A., Racic V., Reynolds P., Salyards K. (eds) Topics on the Dynamics of Civil Structures, Volume 1. Conference Proceedings of the Society for Experimental Mechanics Series. Springer, New York, NY.

Sharafi, P., Hadi, M., \& Teh, L. (2012b), Optimum column layout design of reinforced concrete frames under wind loading. In: Caicedo J., Catbas F., Cunha A., Racic V., Reynolds

Sharafi, P., Samali, B., \& Godrat, M. (2017a). Automated Spatial Design of Multi-Story Modular Buildings Using a Unified Matrix Approach. Automation in Construction, 82, 31-42.

Sharafi, P., Samali, B., Mortazavi, M., \& Ronagh, H. (2017b). Interlocking system for enhancing the integrity of multi-story modular buildings. Automation in Construction, 85, 263-272.

Sharafi, P., Teh, L., \& Hadi, M. (2014a). Shape optimization of thin-walled steel sections using graph theory and ACO algorithm. Journal of Constructional Steel Research, 101, 331 - 341.

Sharafi, P., Teh, L., \& Hadi, M. (2015). Conceptual design optimization of rectilinear building frames: a knapsack problem approach. Engineering Optimization, 47(10), 1303 - 1323.

Thomsen, O. T., Bozhevolnaya, E., \& Lyckegaard, A. (Eds.). (2006). Sandwich Structures 7: Advancing with Sandwich Structures and Materials: Proceedings of the 7th International Conference on Sandwich Structures, Aalborg University, Aalborg, Denmark, 29-31 August 2005. Springer Science \& Business Media.

Tuwair, H., Hopkins, M., Volz, J., ElGawady, M. A., Mohamed, M., Chandrashekhara, K., \& Birman, V. (2015). Evaluation of sandwich panels with various polyurethane foam-cores and ribs. Composites Part B: Engineering, 79, 262-276.

Wang, L., Liu, W., Wan, L., Fang, H., \& Hui, D. (2014). Mechanical performance of foam-filled lattice composite panels in four-point bending: Experimental investigation and analytical modeling. Composites part b: engineering, 67, 270-279.

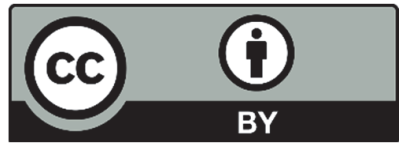

(C) 2018 by the authors; licensee Growing Science, Canada. This is an open access article distributed under the terms and conditions of the Creative Commons Attribution (CC-BY) license (http://creativecommons.org/licenses/by/4.0/). 